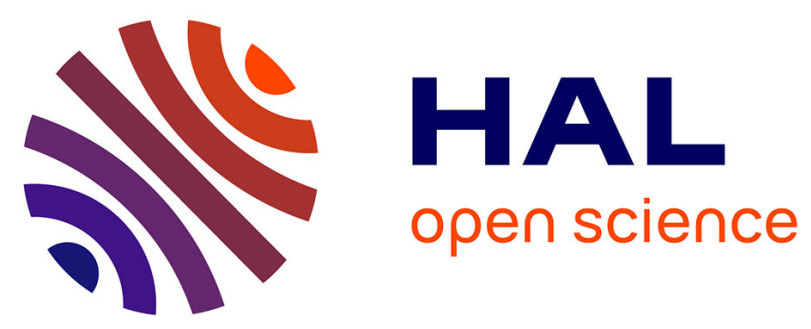

\title{
Quantitative susceptibility mapping in superficial hemosiderosis of the central nervous system
}

Cyril Dargazanli, Jeremy Deverdun, Caroline Lionnet, Stéphanie Michau,

Enes Ozluk, Astrid Corlobé, Xavier Ayrignac, Clarisse Carra-Dallière, Emmanuelle Le Bars, Pierre Labauge, et al.

\section{To cite this version:}

Cyril Dargazanli, Jeremy Deverdun, Caroline Lionnet, Stéphanie Michau, Enes Ozluk, et al.. Quantitative susceptibility mapping in superficial hemosiderosis of the central nervous system. Journal de Neuroradiologie / Journal of Neuroradiology, 2015, 42 (6), pp.370-372. 10.1016/j.neurad.2015.04.007 . hal-01987722

\section{HAL Id: hal-01987722 \\ https://hal.science/hal-01987722}

Submitted on 21 Jan 2019

HAL is a multi-disciplinary open access archive for the deposit and dissemination of scientific research documents, whether they are published or not. The documents may come from teaching and research institutions in France or abroad, or from public or private research centers.
L'archive ouverte pluridisciplinaire HAL, est destinée au dépôt et à la diffusion de documents scientifiques de niveau recherche, publiés ou non, émanant des établissements d'enseignement et de recherche français ou étrangers, des laboratoires publics ou privés. 


\section{Quantitative susceptibility mapping in superficial hemosiderosis of the central nervous system}

\section{Description of the case}

A 19-year-old man with no relevant medical history except a high velocity head trauma a few years earlier was admitted in our institution for sudden onset binocular diplopia. Head-CT performed after the trauma was depicted as being normal. He complained of chronic headaches for about three years, with recent worsening and painkillers resistance.

Clinical examination found binocular ophthalmoplegia with paresis of both abducens nerves.

Non-contrast CT-scan and CT angiography of the circle of Willis were normal. Brain MRIacquisition was performed on a 3T magnet (Skyra, Siemens, Germany) with a 32channel head coil and included a dual-echo Susceptibility Weighted Imaging (SWI), with the following parameters: $T E 1 / T E 2=20 / 40 \mathrm{~ms}, \quad T R=47 \mathrm{~ms}, \quad$ GRAPPA $=2$, voxel size $=1 \times 1 \times 1.5 \mathrm{~mm}, 88$ slices). Conventional sequences showed a subtle distension of the perioptic subarachnoid spaces on coronal T2 sequence (not shown), and a linear loss of signal on pial surface of the left lateral fissure (Fig. 1a). Susceptibility-weighted imaging was performed in order to quantify the related susceptibility effect, through the use of quantitative susceptibility mapping. Marked pial signal loss on T2-GRE and susceptibility-weighted imaging (SWI) was observed at the level of the brainstem, left lateral fissure, cerebellar folia (Fig. 1b-f). Phase image was retrieved from SWlacquisition and underwent laplacian unwrapping as well as background field removal using regularization-enabled SHARPalgorithm. Finally, total variation using split Bregman [1] method enabled images conversion to quantitative susceptibility maps (QSM). Reported susceptibility values were standardized according to the observed cerebrospinal fluid susceptibility. In normal appearing gray matter (Fig. 1g-h), the value was $0.009 \pm 0.1 \mathrm{ppm}$, while in cortico-pial affected areas, measured susceptibility was $0.24 \pm 0.1$ ppm (Fig. 1f), suggesting a paramagnetic effect. Discrete atrophy of the superior cerebellar vermis was also noted (Fig. 1k). T2weighted images of the spinal cord showed a low signal lining on the spinal cord, suggesting hemosiderin deposit (Fig. 1i-j). No acute subarachnoid bleeding was present. Neither MRangiography of the intracranial vessels nor spinal
MRIrevealed any vascular malformation. No intra-axial hemorrhage was found.

Fundoscopic examination revealed bilateral papillary subedema that was confirmed by the fluorescein angiography showing late papillary dye leakage.

Lumbar puncture was finally performed and showed severe intracranial hypertension $\left(57 \mathrm{cmH}_{2} \mathrm{O}\right.$, normal range $7-15 \mathrm{cmH}_{2} 0$ ). Neither erythrocytes nor xantochromia were present.

The diagnosis of superficial siderosis of the central nervous system was made based on the symptoms that were supported by radiological findings.

\section{Discussion}

Superficial siderosis of the central nervous system is a rare disorder resulting from chronic or intermittent bleeding into the subarachnoid space with hemosiderin deposition (blood breakdown products) in the subpial layers of the brainstem, cerebellum, cranial nerves, and spinal cord, leading to slowly progressive neurological dysfunction.

The following etiologies have been reported: $35 \%$ of cases are caused by an idiopathic chronic subarachnoid hemorrhage originating from an occult source and the other cases are secondary to a known cause of subarachnoid hemorrhage such as a current or previous central nervous system tumor (21\%), arteriovenous malformation or aneurysms (9\%), or trauma (13\%). Other less common causes of chronic subarachnoid hemorrhage leading to superficial siderosis are post-operative changes (7\%), brachial plexus injury (6\%), amyloid angiopathy (3\%).

Clinical features are characterized by sensorineural deafness, cerebellar ataxia, pyramidal signs, cognitive decline and bladder disturbance. Chronic increased intracranial pressure and hydrocephalus may occur as a result of obstruction of the ventricular foramina and/or dysfunction of the Pachioni granules, due to hemosiderin deposits. Asymptomatic cases of superficial siderosis are of increasing frequency, because of the rising availability of MRI.

MRI usually shows hemosiderin deposition in the crests of cerebellar folia, superior vermis, eighth cranial nerve, quadrigeminal plate, and basal cerebral surface, but it may also involve interhemispheric fissure, lateral fissures, cortical sulci and pial surface of the spinal cord. Cerebellar atrophy is commonly reported. 

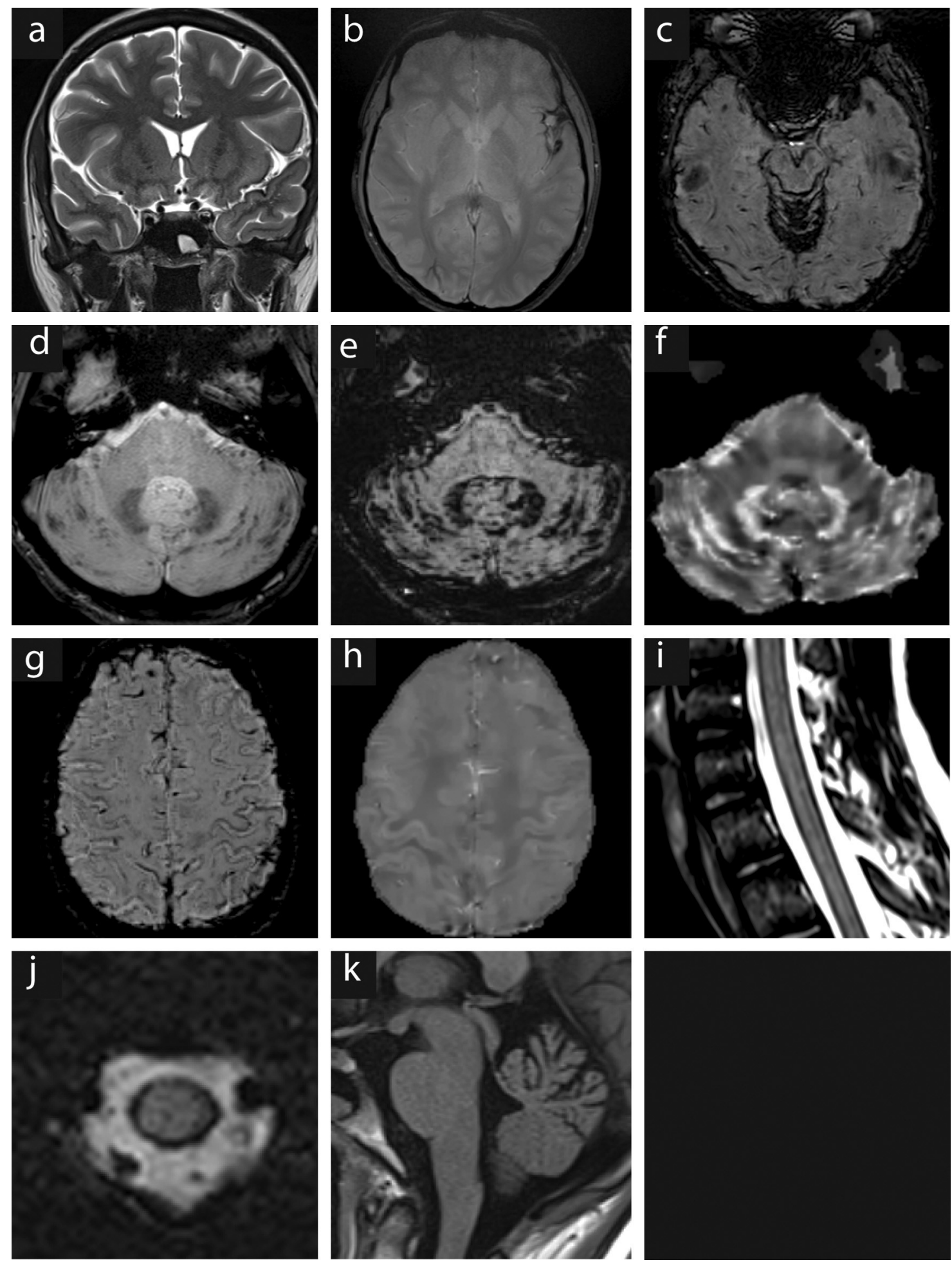

Figure 1 Coronal T2-WI shows a marked loss of signal on pial surface of left insula, frontal and temporal operculum and frontal inferior gyrus (a), observed on axial T2-GRE sequence (b). Magnetic susceptibility artifact outlining mesencephalon, folia of the culmen and cerebellar hemispheres is better seen on SWI(c and e) than on T2-GRE sequence (d). QSMmap reveals hypersignal at the same level, due to a paramagnetic effect (f). Both SWI at the level of centrum semiovale and its corresponding QSMmap show the absence of pathologic hemosiderin deposit or susceptibility artifact ( $\mathrm{g}$ and h). Sagittal T2-WI and axial SWI show thin hemosiderin deposits on the pial surface of the medulla and cervical spinal cord ( $\mathrm{i}$ and $\mathrm{j}$ ). Atrophy of the superior cerebellar vermis is observed on sagittal T1-WI (k). 
In the case series by Kumar et al. [2], 16 patients out of 30 had a fluid-filled collection or pseudomeningocele, mostly in the spinal canal. MRI of the spine is therefore mandatory in case of superficial hemosiderosis.

Cerebrospinal fluid analysis usually shows xanthochromia and elevated erythrocyte count.

Therapy aims at preventing progression of the disease by ablating the source of subarachnoid hemorrhage. Unfortunately, extensive investigation for a source of hemorrhage is rarely fruitful.

SWIsequence is a relatively new sequence. It is becoming a routine practice due to its usefulness in diagnosing diseases accompanied by iron deposition or intracranial calcifications [3].

SWI is more sensitive than T2-GRE for the detection of intra-axial hemorrhage and there is some evidence that SWI is also efficient in detecting extra-axial hemorrhage $[4,5]$. However, it remains a qualitative technique. Quantitative susceptibility maps provide a quantitative analysis of the susceptibility effect and, to our knowledge, there is no published data using QSM in the context of superficial hemosiderosis.

\section{Conclusion}

QSMuniquely allows extraction of numeric data and might be considered as a new biomarker for patients' follow-up in case of evolutive diseases (e.g. superficial hemosiderosis).

\section{Disclosure of interest}

The authors declare that they have no conflicts of interest concerning this article.

\section{References}

[1] Bilgic B, Fan AP, Polimeni JR, Cauley SF, Bianciardi M, Adalsteinsson $E$, et al. Fast quantitative susceptibility mapping with L1-regularization and automatic parameter selection. Magn Reson Med 2014;72(5):1444-59.

[2] Kumar N, Cohen-Gadol AA, Wright RA, Miller GM, Piepgras DG, Ahlskog JE. Superficial siderosis. Neurology 2006;66(8): 1144-52.

[3] Hodel J, Rodallec M, Gerber S, Blanc R, Maraval A, Caron S, et al. [Susceptibility weighted magnetic resonance sequences "SWAN, SWI and VenoBOLD": technical aspects and clinical applications]. J Neuroradiol 2012;39(2):71-86.
[4] Verma RK, Kottke R, Andereggen L, Weisstanner C, Zubler C, Gralla J, et al. Detecting subarachnoid hemorrhage: comparison of combined FLAIR/SWI versus CT. Eur J Radiol 2013;82(9):1539-45.

[5] De Champfleur NM, Langlois C, Ankenbrandt WJ, Le Bars E, Leroy MA, Duffau H, et al. Magnetic resonance imaging evaluation of cerebral cavernous malformations with susceptibility-weighted imaging. Neurosurgery 2011;68(3):641-7 [Discussion 647-8].

$$
\begin{array}{r}
\text { Cyril Dargazanli }{ }^{a} \\
\text { Jérémy Deverdun }{ }^{\mathrm{a}, \mathrm{b}} \\
\text { Caroline Lionnet }^{\mathrm{c}} \\
\text { Stéphanie Michau }^{\mathrm{d}} \\
\text { Enes Ozluk }^{\mathrm{e}} \\
\text { Astrid Corlobé }^{\mathrm{c}} \\
\text { Xavier Ayrignac }{ }^{\mathrm{c}} \\
\text { Clarisse Carra-Dallière }^{\mathrm{c}} \\
\text { Emmanuelle Le Bars }^{\mathrm{a}} \\
\text { Pierre Labauge }^{\mathrm{c}} \\
\text { Alain Bonafé }^{\mathrm{a}}
\end{array}
$$
Nicolas Menjot de Champfleur ${ }^{\mathrm{a}, *}$ a Department of Neuroradiology, Gui de Chauliac Hospital, Montpellier University Hospital Center, 34091 Montpellier cedex 5, France

${ }^{\text {b } C N R S ~ U M R ~ 5221, ~ M o n t p e l l i e r ~ I I ~ U n i v e r s i t y, ~} 34000$ Montpellier, France

c Department of Neurology, Gui de Chauliac Hospital, Montpellier University Hospital Center, 34091 Montpellier cedex 5, France

dDepartment of Ophtalmology, Gui de Chauliac Hospital, Montpellier University Hospital Center, 34091 Montpellier cedex 5, France

e Radiology Department, Cerrahpas, a Faculty of Medicine, Istanbul, Turkey

* Corresponding author.

E-mail addresses: c.dargazanli@gmail.com (C. Dargazanli), jeremy.deverdun@neuf.fr (J. Deverdun), caroline.lionnet@gmail.com (C. Lionnet), s.michau@hotmail.fr (S. Michau), enesozluk@yahoo.com (E. Ozluk), astrid.corlobe@gmail.com (A. Corlobé), x-ayrignac@chu-montpellier.fr (X. Ayrignac), clarisse.carra@gmail.com (C. Carra-Dallière), e-le_bars@chu-montpellier.fr (E. Le Bars), labauge@yahoo.fr (P. Labauge), a-bonafe@chu-montpellier.fr (A. Bonafé), nicolasdechampfleur@orange.fr (N. Menjot de Champfleur) 